\title{
Sin stocks and ESG scores: Does the nature of your business really matter?
}

\author{
Edgardo Cayón \\ Department of Finance, CES A Business School \\ Colombia \\ ecayon@,cesa.edu.co \\ ORCID 0000-0002-4113-5521

\section{Juan Camilo Gutierrez} \\ Direct TV \\ Colombia \\ juangutierrezdepineres@,hotmail.com
}

Abstract. The purpose of this paper is to analyse the environmental, social, and governance (ESG) performance of sin stocks held by companies that operate in sectors with ethical implications (gaming, defence, adult entertainment, etc.). For this purpose, the model of choice was a panel based on the stocks of the global S\&P 1200 index for the period between 2014 and 2018, for which the accounting data was available at the time of the study. The panel model accounted for different control variables and non-sin ESG performance. Having analysed its results, we have found that the ESG performance of sin stocks is positively correlated to future ESG performance, which was a surprise given that most of the analysed companies operate in sectors that are deemed as socially and ethically controversial. One hypothesized explanation for this is the phenomenon of "social cleaning", when a company engages in ESG activities with the sole purpose of reducing reputational risk while trying to attract a wider base of socially aware investors. Therefore, we conclude that in order to avoid the risk of "social cleaning" ESG rating companies should give more weight to environmental and social factors rather than governance ones, especially in the case of sin stocks.

Keywords: Corporate Governance, social cleaning, paned data, CSR, ratings, performance

JEL Classification: G3, G30 


\section{INTRODUCTION}

Currently, corporate social responsibility (CSR) has become an important topic in business. According to the KPMG Survey of Sustainability Reporting 2020, more than $80 \%$ of the biggest companies in the world are reporting their sustainability performance, which is a threefold increase from 17 years ago. Nowadays, one of the top concerns of most companies lies on how their business activities affect society as a whole. There is a growing field of research on the subject of CSR and its impact on investors. One common measure that many investors use to rank CSR is the environmental, social, and governance (ESG) index. Cappucci (2018) discusses the paradox of ESG investment, which states that even though investors realize that solid ESG investments should yield higher returns, in reality the cost of having a fully integrated ESG strategy can offset the financial benefits deriving from those investments. The author has found that in the majority of the mutual funds interviewed, any strategy concerning ESG compliance in their investments was accomplished through third parties. Therefore, in the case of $70 \%$ of the investment companies in the sample, it was possible that ESG investments were done without any real evidence of compliance by the companies the funds invested in (Cappucci, 2018).

\section{LITERATURE REVIEW}

\subsection{The relevance of ESG ratings}

Park \& Ravenel (2013) argue that ESG quantitative measures have yet to earn its respect and legitimacy in the eyes of the financial and investment industry. These authors assert that any improvement of the metrics and the use of ESG depends on the continued use of standardized frameworks that something becomes quantitatively measurable. Therefore, the challenge for ESG measures lies on how to quantify the value of clean air, water, carbon emissions, and other larger initiatives that have a positive impact on society. In a recent paper by Fatemi, Glaum, \& Kaiser (2018) examining how valuation is affected by the level of disclosure of ESG activities in firms, contrary to general belief, they found that a high level of disclosure of ESG activities that are solely focused on the strength of the companies on these areas had a negative impact on company valuation. On the other hand, high disclosure on ESG activities that showed the weakness of the company was received favorably by investors. One plausible explanation by the authors was that ESG disclosure that is focused on strengths was received with skepticism by investors; on the contrary, ESG disclosure focused on correcting weakness was received as a signal of improved management performance (Fatemi et al., 2018).

\subsection{ESG and financial performance}

Another line of research addresses the issue of superior financial performance of ESG investments, and the empirical evidence is mixed. For example, Limkriangkrai, Koh, \& Durand (2017) found evidence that at least for Australian firms, there was no evidence that stocks with a high ESG rating outperformed those with ESG lower ratings. Further, they determined that firms with high ESG ratings had more debt than those with lower ESG ratings. On a similar line of research, Ng \& Rezaee (2015) found that when controlling ESG performance with other factors such as the firm's growth opportunities, operational efficiency, and research efforts, the firms with higher ESG ratings had a lower cost of capital. In both previous studies, they found evidence that the ESG factors that had an effect on financial performance were the environmental factor and the one related with governance; meanwhile, in the case of the social factor, the effects of the cost of capital and financial performance were deemed negligible. On the other hand, Verheyden, Eccles, \& Feiner (2016) found that screening for improved ESG performance can outperform 
traditional investments of the same class in terms of risk and return. In their study, the authors use a global sample of stocks to conform portfolios of the $10 \%$ and $25 \%$ top performers in ESG ratings and compared their performance with similar portfolios without ESG screening. The authors found that in the case of the $10 \%$ top performers, the portfolio outperformed its unscreened counterpart in terms of risk and return, but this was not the case for the $25 \%$ top performers' screened portfolio. A similar study conducted by Halbritter \& Dorfleitner (2015) found that there was no statistical evidence that high rated ESG companies outperformed low rated ones. Basing their analysis on the data obtained from the three major providers of ESG ratings (Bloomberg, KLD, and ASSET4) using different asset pricing models in order to test the robustness of their results, the authors concluded that there was no evidence of a strong relation between ESG and financial performance.

\subsection{ESG and firm value}

Other studies have been focused on the different ESG components and their relationship with firm value. Of special importance is corporate governance, for example, Brown and Caylor (2006) have studied how this factor is particularly relevant to firm valuation and which internal guidelines in regard to minimizing agency costs influence the most. They concluded that the factors that have more influence were the ones that addressed executive compensation and board independence as well as other measures designed to avoid the principal-agent conflict. Similarly, Derwall, Koedijk, \& Horst (2011) did a comprehensive literature review of socially responsible investment (SRI), wherein they explained the superior performance of low ESG rating stocks or "sin stocks" over a short period of time using the shunned shock hypothesis. This hypothesis states that since a value-driven investor would avoid the "controversial" or "sin" stock, this leads to an undervaluation of the stock due to reduced demand for it, which, in turn, becomes an arbitrage opportunity to the profit-driven investor in the short run. On the other hand, superior performance in the long run of high performing ESG stocks can be explained using the error-in-expectations hypothesis in which profit-investors undervalue the impact of CSR in the short run, thus creating the same misbalance in demand that becomes an arbitrage opportunity for the value-driven investor in the long run. Furthermore, Borgers et al. (2015) tested the hypothesis if socially responsible investments had a significant impact on investment performance in the US equity mutual fund industry for the period between January 2004 and December 2012. As per their findings, there is no evidence that social considerations can influence investment choices regarding the exposure to controversial and high performing ESG stocks.

\subsection{ESG and investment strategy}

Finally, research with regard to ESG have only not focused on the general financial performance of funds, but also on investment strategies. Jain, Jain, \& Rezaee (2016) have looked into the question of whether short sellers included ESG analysis in their investment decisions or not. The authors conclude that ESG information can be relevant for short sellers, as there is a positive relationship between low ESG performance and short selling. A lower performance on ESG ratings is usually a signal to short sellers to increase their position on a particular asset. Henke (2016) used a matching procedure to test the performance of socially responsible bonds versus a control sample. The author found that bonds from socially responsible companies outperformed their conventional counterparts and that bond fund managers tend to exclude those bonds with the lowest ESG ratings. In this present study, control variables for common characteristics are used in order to see the ESG performance of sin stocks in terms of ranking when compared to other stocks in a global index. 


\section{METHODOLOGY}

The data for this present paper was compiled from Bloomberg. Our dataset is comprised of all the stocks that have been into the S\&P Global 1200 from 2014 to 2018. The panel is unbalanced and takes into account all the stocks that have been in and out of the index at some point in time in order to avoid survivorship bias. Based on the accounting and market data of the companies that compose the index, we have calculated the following explanatory variables found in the literature and are used to explain ESG performance. In Table 1, we can observe a summary of the variables for the whole sample. In order to categorize a stock as a sin stock, we used a similar categorization as that of Baron et al. (2011), but excluding certain ethical sectors (biotech, nuclear energy, and oil), except for the defense industry.

Table 1

Summary of explanatory variables

\begin{tabular}{|l|l|}
\hline Independent variables & Formula \\
\hline Tobin's Q & Market capitalization/book value \\
\hline Return on equity (ROE) & Net income/equity \\
\hline Return on assets (ROA) & Net income/total assets \\
\hline Growth & LN (revenue year 2/revenue year 1) \\
\hline Total assets/revenue & Total assets/revenue \\
\hline Debt & Debt/equity \\
\hline R\&D/revenue & R\&D/revenue \\
\hline PPE/total assets & PPE/total assets \\
\hline Liquidity & Volume/shares outstanding \\
\hline EPS & EPS \\
\hline
\end{tabular}

Source: own compilation

The dependent variable is the ESG rank of a particular firm, retrieved from Bloomberg, based on RobecoSAM data. The ESG ranks the company in a scale of 100, being 100 as the highest score. In total, for our panel, we obtained 4490 data points per variable calculated in an annual basis. The panel was filtered for inconsistencies and ended with a balanced panel with 3441 observations per variable. In Table 2, we can observe the descriptive statistics of the variables in question. From the statistics presented, we can observe that the composite ESG score has a lower standard deviation than the individual environmental and governance scores. Also, the governance score standard deviation is lower than the one of the composite score, and the median of the governance score is higher than those of the individual environmental and social scores. This means that in a certain way, the governance component has more weight in the composite score than the environmental and social components. This makes sense, because according to RobecoSAM (2019), different weightings are given to different GICS (Global Industry Classification Standards) sectors. For example, in the case of the gaming industry, which in many cases can be categorized as a sin stock, a component of the economic dimension, such as corporate governance, is given a weight of $8 \%$, while a component of the social dimension such as corporate citizenship and philanthropy is given a weight of 2 $\%$. Another example is the case of tobacco, wherein the relationship is $9 \%$ for corporate governance and 3 $\%$ for corporate citizenship and philanthropy. Finally, in the case of aerospace and defense, the relationship is $8 \%$ for corporate governance and $2 \%$ for corporate citizenship and philanthropy. 
Descriptive statistics

\begin{tabular}{|l|c|c|c|c|c|c|c|}
\hline & ESG & $\begin{array}{c}\text { ENVIRONME } \\
\text { NTAL }\end{array}$ & $\begin{array}{c}\text { GOVERNANC } \\
\text { E }\end{array}$ & SOCIAL & TOBIN'S Q & ROE & ROA \\
\hline Mean & 53.03738 & 38.16761 & 71.30816 & 49.63638 & 2.734091 & 0.416753 & 0.122587 \\
\hline Median & 54.96209 & 39.57131 & 75.56393 & 51.45729 & 2.723200 & 0.122631 & 0.051250 \\
\hline Maximum & 90.05869 & 99.12281 & 93.06543 & 97.97203 & 540.0126 & 153.1403 & 27.25108 \\
\hline Minimum & 6.564064 & 0.000000 & 5.405405 & 0.000000 & -1683.605 & -118.7046 & -3.340111 \\
\hline Std. Dev. & 16.85519 & 31.25548 & 13.09547 & 24.45581 & 43.49379 & 4.977531 & 0.726243 \\
\hline Skewness & -0.217260 & 0.125884 & -1.010965 & -0.568471 & -23.22290 & 12.99214 & 27.86238 \\
\hline Kurtosis & 2.191950 & 1.662969 & 3.470725 & 2.674413 & 765.1486 & 470.9171 & 900.0276 \\
\hline Observations & 4490 & 4490 & 4490 & 4490 & 4490 & 4490 & 4490 \\
\hline
\end{tabular}

\begin{tabular}{|l|c|c|c|c|c|c|c|}
\hline & GROWTH & TA/R & DEBT & $\begin{array}{c}\text { R\&D/REVE } \\
\text { NUE }\end{array}$ & PPE/TA & LIQUIDITY & EPS \\
\hline Mean & 0.034045 & 2.862362 & 1.185705 & 0.037769 & 0.280659 & 0.733532 & 5.319580 \\
\hline Median & 0.036828 & 1.537450 & 0.589657 & 0.004609 & 0.203593 & 0.638832 & 2.004200 \\
\hline Maximum & 4.670859 & 398.3409 & 422.4658 & 1.473956 & 0.971095 & 5.958722 & 2066.763 \\
\hline Minimum & -2.387765 & 0.180081 & -201.3550 & 0.000000 & 0.000124 & 0.000709 & -93.33080 \\
\hline Std. Dev. & 0.187186 & 15.84027 & 12.19661 & 0.078594 & 0.234622 & 0.450171 & 61.82718 \\
\hline Skewness & 2.590127 & 20.23565 & 24.00564 & 5.477048 & 0.946835 & 2.371066 & 29.38222 \\
\hline Kurtosis & 104.9645 & 432.7205 & 859.3147 & 59.74927 & 2.892625 & 15.88697 & 885.5758 \\
\hline Observations & 4490 & 4490 & 4490 & 4490 & 4490 & 4490 & 4490 \\
\hline
\end{tabular}

Source: own compilation

Therefore, it is possible, under this type of metric, for a sin stock that scores strongly on corporate governance to have a high composite ESG score. From the companies that have been included in our sample, we identified that 94 of them belong to the tobacco, alcohol, defense, and gaming industries which belong to GICS the consumer discretionary $(23.40 \%)$, consumer staples $(40.43 \%)$ and industrial sectors $(36.17 \%)$.When we compare the average rank scores for the different sectors, we find that the average ESG score for sin stocks in the consumer discretionary sector was $40.73 \%$, consumer staples $60.04 \%$, and industrials $53.96 \%$. For the same sectors, the average of non-sin companies was $49.47 \%$ for consumer discretionary, consumer staples $56.51 \%$, and industrials $49.30 \%$. We can see that for two of the sectors, the composite ESG rank is higher for sin stocks. After identifying the ESG composite scores for the companies in the sample, we ranked all the companies in the S\&P Global 1200 index according to their ESG score and did the same exercise as before, for the top $25 \%$ companies in terms of ESG scores and the bottom $25 \%$. Additionally, we also did the same exercise for each of the three components of the ESG score (environmental (E), social (S), and governance $(\mathrm{G})$ ). The results are summarized in Table 3.

As shown in the table, we can observe that when compared to the non-sin (general) companies' average, sin companies outperform the general composite scores in the consumer staples and industrial sectors with the exception of the consumer discretionary sector. In the environmental aspect, the general scores outperform all of those of sin companies with the exception of the consumer staple sector. In the social aspect, sin stocks just outperform its general counterparts in the industrial sector, whereas in the governance aspect, the general companies' score outperform its sin counterparts in all sectors. For those companies in the top $25 \%$ in terms of composite and individual scores, they outperform sin stocks in all areas but one. Interestingly, the area in question is concern with social in the industrial sectors where most of the sin companies in this sector belong to the defense subsector. Finally, for those companies in the bottom $25 \%$, sin companies were noted to have outperformed the bottom companies in terms of the composite scores for all the observed sectors. In the environmental aspect, sin companies outperform the bottom companies in the consumer staple sectors alone; meanwhile, in terms of social and governance 
scores, sin companies have outperformed all their counterparts ranked at the bottom of the scale. Therefore, we can hypothesize that in the case of the companies of the S\&P Global 1200 index for the period in question, the fact that a company is categorized as a sin stock does not necessarily affect the company's composite ESG score. Escrig-Olmedo et al. (2019) pointed out that almost all ESG rating agencies fail in assessing comprehensive sustainability measures in their scores, and the way they weight the different ESG components depending on the sector can bias the results toward potential investors. However, it is important to mention that from the data, we can infer that sin stocks tend to rank lower in terms of environmental aspects than all other observed companies in the index.

Table 3

Comparison of ESG scores among sin industries GICS sectors

\begin{tabular}{|c|c|c|c|}
\hline & $\begin{array}{c}\text { Consumer } \\
\text { Discretionary }\end{array}$ & $\begin{array}{l}\text { Consumer } \\
\text { Staples }\end{array}$ & Industrials \\
\hline ESG composite (Sin) & 40.73 & 60.04 & 53.96 \\
\hline Environmental (Sin) & 21.82 & 53.93 & 29.60 \\
\hline Social (Sin) & 32.19 & 58.12 & 57.50 \\
\hline Governance (Sin) & 68.18 & 68.08 & 74.79 \\
\hline ESG composite (General) & 49.47 & 56.51 & 49.30 \\
\hline Environmental (General) & 34.16 & 47.26 & 32.79 \\
\hline Social (General) & 43.38 & 51.36 & 45.32 \\
\hline Governance (General) & 70.87 & 70.91 & 69.79 \\
\hline ESG composite (25\% T-ESG) & 66.64 & 70.10 & 71.41 \\
\hline Environmental (25\% T-E) & 47.49 & 61.86 & 53.06 \\
\hline Social $(25 \%$ T-S $)$ & 49.15 & 64.06 & 56.92 \\
\hline Governance $(25 \% \mathrm{~T}-\mathrm{G})$ & 49.79 & 64.51 & 52.07 \\
\hline ESG Composite (25\% B-ESG) & 30.87 & 26.83 & 29.94 \\
\hline Environmental $(25 \%$ B-E) & 47.67 & 50,97 & 47,66 \\
\hline Social $(25 \%$ B-S $)$ & 28.16 & 24.78 & 27.29 \\
\hline Governance $(25 \%$ B-G) & 46.28 & 56.45 & 48.43 \\
\hline
\end{tabular}

Note: Table 3 shows the average composite and individual ESG scores for the sin companies GICS sectors. We also compare the general composite and individual scores of non-sin companies in the same GICS sectors as well as those ranked in the top and bottom $25 \%$ of our sample.

Source: own compilation

In order to analyze the data, the first step is to run a factor model with the following specification:

$$
\operatorname{ESGRANK}_{i, t}=\alpha_{0}+\beta_{l}{ }^{\prime} X_{i, t-1}+\gamma_{0} \operatorname{SIN}_{i, t}+\gamma_{1} Q U A N T I L E_{i, t-1}+\varepsilon_{i, t}
$$

where ESGRANK is the composite scores in ranking orders, being $100 \%$ the highest and so forth and ' $X_{i, t-1}$ is a vector that contains all the explanatory variables of Table 1 lagged one period to address endogeneity issues. $\mathrm{SIN}_{\mathrm{i}, \mathrm{t}}$ is dummy variable that takes the value of 1 if the company is categorized as a sin stock and 0 otherwise, which we categorized in a similar manner as that of Baron et al. (2011). QUANTILE $\mathrm{i}_{\mathrm{i}, \mathrm{t}-1}$ is a dummy variable that takes the value of 1 if the company ranks in a specific quantile of the composite or each individual score component (in the case of the companies in our sample the dummy top $25 \%$ ESG means that the companies with a ranking greater than $75 \%$ take the value of 1 and 0 otherwise, inversely in the case of bottom $25 \%$ ). The regression is run with white corrected errors. 


\section{EMPIRICAL RESULTS AND DISCUSSION}

We summarize the results of our regression using equation (1) where we also control for company and year effects (Table 4).

Table 4

Results of the panel regression

\begin{tabular}{|c|c|c|c|c|c|}
\hline & ESG RANK & TOP $25 \%$ ESG & TOP $25 \% \mathrm{E}$ & TOP $25 \% \mathrm{~S}$ & TOP $25 \% \mathrm{G}$ \\
\hline \multirow{2}{*}{$Q^{- \text {Tobin }_{t-1}}$} & $-0.0190^{*}$ & $-0.0208^{*}$ & $-0.0195^{*}$ & $-0.0194^{*}$ & $-0.0182^{*}$ \\
\hline & $(0.0108)$ & $(0.0112)$ & $(0.0109)$ & $(0.0107)$ & $(0.0107)$ \\
\hline \multirow{2}{*}{$\mathrm{ROE}_{t-1}$} & 0.0012 & 0.0011 & 0.0010 & 0.0012 & 0.0012 \\
\hline & $(0.0009)$ & $(0.0009)$ & $(0.0009)$ & $(0.0009)$ & $(0.0009)$ \\
\hline \multirow[t]{2}{*}{$\mathrm{RO} A_{t-1}$} & -0.0001 & -0.0001 & -0.0001 & -0.0001 & -0.0001 \\
\hline & $(0.0001)$ & $(0.0001)$ & $(0.0001)$ & $(0.0001)$ & $(0.0001)$ \\
\hline \multirow[t]{2}{*}{ Growth $_{t-1}$} & $-0.0398^{* * *}$ & $-0.0367 * * *$ & $-0.0372^{* * *}$ & $-0.0397 * * *$ & $-0.0397 * * *$ \\
\hline & $(0.0029)$ & $(0.0028)$ & $(0.0028)$ & $(0.0029)$ & $(0.0029)$ \\
\hline \multirow[t]{2}{*}{ Total assets/ revenue $t-1$} & -0.0035 & -0.0021 & -0.0024 & -0.0035 & -0.0033 \\
\hline & $(0.0041)$ & $(0.0041)$ & $(0.0041)$ & $(0.0041)$ & $(0.0040)$ \\
\hline \multirow[t]{2}{*}{ Debt $_{t-1}$} & 0.0003 & 0.0003 & 0.0003 & 0.0003 & 0.0003 \\
\hline & $(0,0003)$ & $(0,0003)$ & $(0.0003)$ & $(0.0003)$ & $(0.0040)$ \\
\hline \multirow[t]{2}{*}{ RED/revenue $_{t-1}$} & $-0.2247 * * *$ & $-0.2042^{* *}$ & $-0.2007 * *$ & $-0.2241 * * *$ & $-0.2278^{* * *}$ \\
\hline & $(0.0791)$ & $(0.0796)$ & $(0.0795)$ & $(0.0791)$ & $(0.0793)$ \\
\hline \multirow[t]{2}{*}{ PPE/total assets $s_{t-1}$} & -0.0020 & 0.0015 & -0.0047 & -0.0024 & 0.0007 \\
\hline & $(0.0262)$ & $(0.0258)$ & $(0.0259)$ & $(0.0791)$ & $(0.0262)$ \\
\hline \multirow[t]{2}{*}{ Liquidity $_{t--1}$} & $-0.0379 * * *$ & $-0.0393^{* * *}$ & $-0.0387 * * *$ & $-0.0379 * * *$ & $-0.0388^{* * *}$ \\
\hline & $(0.0113)$ & $(0.0113)$ & $(0.0113)$ & $(0.0113)$ & $(0.0113)$ \\
\hline \multirow[t]{2}{*}{$E P S_{t-1}$} & $-0.0001 * * *$ & $-0.0001 * * *$ & $-0.0001 * * *$ & $-0.0001 * * *$ & $-0.0001 * * *$ \\
\hline & $(0.0000)$ & $(0.0000)$ & $(0,0000)$ & $(0,0000)$ & $(0.0000)$ \\
\hline \multirow[t]{2}{*}{ Sin stock } & $0.0612^{* *}$ & $0.0536^{*}$ & $0.0606^{* *}$ & $0.0610^{* *}$ & $0.0615^{* *}$ \\
\hline & $(0.0302)$ & $(0.0302)$ & $(0.0298)$ & $(0.0301)$ & $(0.0303)$ \\
\hline \multirow[t]{2}{*}{ Dummy quantile ${ }_{t-1}$} & & $-0.0734 * * *$ & $-0.0678^{* * *}$ & -0.0110 & $-0.0217^{*}$ \\
\hline & & $(0.0119)$ & $(0.0121)$ & $(0.0153)$ & $(0.0115)$ \\
\hline Adjusted $\mathrm{R}^{2}$ & 0.2061 & 0.2183 & 0.2156 & 0.2060 & 0.2070 \\
\hline Number of observations & 3441 & 3441 & 3441 & 3441 & 3441 \\
\hline Company effects & Yes & Yes & Yes & Yes & Yes \\
\hline Year effects & Yes & Yes & Yes & Yes & Yes \\
\hline
\end{tabular}


Table 4

Results of the panel regression (cont.)

\begin{tabular}{|c|c|c|c|c|}
\hline & $\begin{array}{c}\text { BOTTOM } 25 \\
\% \text { ESG }\end{array}$ & $\begin{array}{c}\text { BOTTOM } 25 \\
\% \mathrm{E}\end{array}$ & $\begin{array}{c}\text { BOTTOM } 25 \\
\% \mathrm{~S}\end{array}$ & $\begin{array}{c}\text { BOTTOM } 25 \\
\% \mathrm{G}\end{array}$ \\
\hline \multirow[t]{2}{*}{ Q-Tobin $t-1$} & $-0.0180^{*}$ & $-0.0204^{*}$ & $-0.0191 *$ & $-0.0193^{*}$ \\
\hline & $(0.0108)$ & $(0.0106)$ & $(0.0106)$ & $(0.0109)$ \\
\hline \multirow[t]{2}{*}{$\mathrm{ROE}_{t-1}$} & 0.0012 & 0.0013 & 0.0012 & 0.0012 \\
\hline & $(0.0009)$ & $(0.0009)$ & $(0.0009)$ & $(0.0009)$ \\
\hline \multirow[t]{2}{*}{$\mathrm{RO} A_{t-1}$} & -0.0001 & -0.0001 & -0.0001 & -0.0001 \\
\hline & $(0.0001)$ & $(0.0001)$ & $(0.0001)$ & $(0.0001)$ \\
\hline \multirow[t]{2}{*}{ Growth $_{t-1}$} & $-0.0375^{* * *}$ & $-0.0393 * * *$ & $-0.0390 * * *$ & $-0.0399 * * *$ \\
\hline & $(0.0029)$ & $(0.0029)$ & $(0.0029)$ & $(0.0029)$ \\
\hline \multirow[t]{2}{*}{ Total assets/ revenue $_{t-1}$} & -0.0035 & -0.0041 & -0.0033 & -0.0038 \\
\hline & $(0.0041)$ & $(0.0041)$ & $(0.0041)$ & $(0.0041)$ \\
\hline \multirow[t]{2}{*}{$\operatorname{Debt}_{t-1}$} & 0.0002 & 0.0003 & 0.0003 & 0.0003 \\
\hline & $(0.0003)$ & $(0.0003)$ & $(0.0003)$ & $(0.0003)$ \\
\hline \multirow[t]{2}{*}{ R\&D/revenue $_{t-1}$} & $-0.2276^{* * *}$ & $-0.2329 * * *$ & $-0.2242^{* * *}$ & $-0.2145^{* * *}$ \\
\hline & $(0.0803)$ & $(0.0792)$ & $(0.0792)$ & $(0.0791)$ \\
\hline \multirow[t]{2}{*}{ PPE/total assets $t_{t-1}$} & 0.0028 & 0.0000 & -0.0017 & 0.0024 \\
\hline & $(0.0260)$ & $(0.0261)$ & $(0.0262)$ & $(0.0791)$ \\
\hline \multirow[t]{2}{*}{ Liquidity $_{t-1}$} & $-0.0389 * * *$ & $-0.0374 * * *$ & $-0.0382^{* * *}$ & $-0.0403^{* * *}$ \\
\hline & $(0.0112)$ & $(0.0113)$ & $(0.0113)$ & $(0.0114)$ \\
\hline \multirow[t]{2}{*}{$E P S_{t-1}$} & $-0.0001 * * *$ & $-0.0001^{* * *}$ & $-0.0001 * * *$ & $-0.0002^{* * *}$ \\
\hline & $(0.0000)$ & $(0.0000)$ & $(0.0000)$ & $(0.0000)$ \\
\hline \multirow[t]{2}{*}{ Sin stock } & $0.0634^{* *}$ & $0.0624 * *$ & $0.0620^{* *}$ & $0.0658^{* *}$ \\
\hline & $(0.0298)$ & $(0.0304)$ & $(0.0300)$ & $(0.0304)$ \\
\hline \multirow[t]{2}{*}{ Dummy quantile $t_{t-1}$} & $0.0545^{* * *}$ & $0.0624 * *$ & $0.0279 *$ & $0.0437 * * *$ \\
\hline & $(0.0125)$ & $(0.0304)$ & $(0.0150)$ & $(0.0150)$ \\
\hline Adjusted $\mathrm{R}^{2}$ & 0.2122 & 0.2098 & 0.2069 & 0.2083 \\
\hline Number of observations & 3441 & 3441 & 3441 & 3441 \\
\hline Company effects & Yes & Yes & Yes & Yes \\
\hline Year effects & Yes & Yes & Yes & Yes \\
\hline
\end{tabular}

Note: This table reports the results of the panel regression: $E S G R A N K_{i, t}=\alpha_{0}+\beta_{l}{ }^{\prime} X_{i, t-1}+\gamma_{0} S_{I} N_{i, t}+\gamma_{1} Q U A N T I L E_{i, t-1}+\varepsilon_{i, t}$ where ' $X_{i, t-1}$ is a vector that contains all the explanatory variables of Table 1 lagged one period. SIN $\mathrm{i}_{\mathrm{i}, \mathrm{t}}$ is dummy variable that takes the value of 1 if the company is categorized as a sin stock and 0 otherwise. DUMMY QUANTILE $\mathrm{i}_{\mathrm{i}, \mathrm{t}-1}$ is a dummy variable that specifies the quantile of the composite and each individual score as described at the top of the table (e.g., TOP $25 \%$ ESG means that any company with a rank greater than $75 \%$ in the composite score takes the value of 1 or 0 otherwise)

Source: own compilation

As presented in Table 4, we can observe that the significant control variables that explain the variance in ESG ranking are the Tobin's Q, growth, R\&D/revenue, and liquidity. Sin stocks seem to be positively correlated with ESG ranking. Sin stocks tend to improve for all observed specifications when controlled by quantile average of $6.10 \%$ in the ESG ranking when compared with their ESG ranking the year before. On the contrary, certain control variables such as the Tobin's Q, growth (measured as growth in revenue), $\mathrm{R} \& \mathrm{D} /$ revenue, and liquidity have been determined to be inversely correlated with the company's ESG ranking. In the case of market capitalization (Tobin's Q), the average impact on the ESG ranking is around 
$-1.94 \%$, which means that companies with a higher market capitalization rank lower in the next year's rank than in the preceding year. In the case of growth, the average impact is $-3.89 \%$, which means that average companies that experience a growth in sales tend to rank higher in the preceding year. In the case of $\mathrm{R} \& \mathrm{D} /$ revenue and liquidity, the average impact is $-21.91 \%$ and $-3.85 \%$, respectively. Finally, when controlling for quantiles, we obtain some interesting results, for example, the companies that scored on the top $25 \%$ in terms of composite ESG the preceding year tend to fall in average $7.14 \%$ the following year; meanwhile, those in the bottom $25 \%$ the previous year tend to improve an average of $5.45 \%$ the following year. In the case of the environmental score, the average impact tends to be $-6.75 \%$, and for the bottom $25 \%$, it is $6.24 \%$. In the case of the social score, the fact that a company is in the top $25 \%$ does not have a significant effect on the next year's ESG score. However, if the company is in the bottom $25 \%$ of this category the year before, it improves an average of $2.79 \%$ in terms of the ESG composite score. Finally, in the case of the governance score, if a company is in the top $25 \%$ in the preceding year, this has a negative impact of $-2.17 \%$ in the next year's score; on the contrary, companies in the bottom $25 \%$ tend to improve their next year's ESG composite score, that is, an average of $4.37 \%$.

Although it seems that the results are counterintuitive at first, we can observe that in terms of ESG performance, companies categorized as sin stocks tend to improve when compared with other companies in the index. There is evidence that this is the case, for example, Garcia et al. (2017) found out that "sensitive sectors" that could be categorized as sin stocks in emerging market outperformed their peers in terms of environmental performance. Our results also show evidence of a recent phenomenon that has been categorized by the financial press as "social cleaning," which regards ESG ranking as a simple tool to enhance and minimize ESG-derived controversies while broadening their base of socially aware investors (Porter et al., 2019). If indeed, there is "social cleaning" by sin stocks; this can explain why it seems that sin stocks' ESG ranking tends to be positively correlated to ESG composite performance. Finally, we can observe that as a whole, ESG rankings are competitive, as top performers find it hard to maintain their current rankings (which are inversely correlated to next year performance). This is compounded by the fact that the bottom $25 \%$ performers tend to improve from their previous ranking to the next year ranking in both the composite and individual ESG scores.

\section{CONCLUSION}

Based on the stocks of the S\&P Global 1200 index for the period between 2014 and 2018, in which we analyzed the information concerning the stocks overall ESG performance as well as their individual environmental, social, and governance components, we have found that companies categorized as sin companies are positively correlated with overall ESG performance; on the contrary, non-sin companies ranked in top $25 \%$ and bottom $25 \%$ in terms of ESG performance are negatively correlated with next years' ESG performance both at the composite and individual level. We hypothesize that one plausible explanation can be that a certain degree of "social cleaning" can be the driving force behind ESG performance of sin companies and bottom performers. Future research should thus focus on the potential bias of ESG composite scores due to "social cleaning" by controversial companies. If indeed the rating companies does not change the weightings given for ethical controversial sector, there is a chance that the phenomena of "social cleaning" will increase in the following years.

\section{ACKNOWLEDGMENT}

The authors are thankful to CESA Business School for their support. 


\section{REFERENCES}

Baron, D. P., Harjoto, M. A., \& Jo, H. (2011). The economics and politics of corporate social performance. Business and Politics, 13(2), 1-46.

Borgers, A., Derwall, J., Koedijk, K., \& Horst, J. t. (2015). Do social factors influence investment behavior and performance? Evidence from mutual fund holdings. Journal of Banking \& Finance, 112-126.

Brown, L. D., \& Caylor, M. L. (2006). Corporate governance and firm valuation. Journal of Accounting and Public Policy, 409-434.

Cappucci, M. (2018). The ESG Integration Paradox. Journal of Applied Corporate Finance, 30(2), 22-28. doi: $10.1111 /$ jacf.12296

Derwall, J., Koedijk, K., \& Horst, J. T. (2011). A tale of values-driven and profit-seeking social investors. Journal of Banking \& Finance, 2137-2147.

Escrig-Olmedo, E., Fernández-Izquierdo, M. Á., Ferrero-Ferrero, I., Rivera-Lirio, J. M., \& Muñoz-Torres, M. J. (2019). Rating the raters: Evaluating how ESG rating agencies integrate sustainability principles. Sustainability, 11(3), 915.

Fatemi, A., Glaum, M., \& Kaiser, S. (2018). ESG performance and firm value: The moderating role of disclosure. Global Finance Journal, 38, 45-64. doi: https://doi.org/10.1016/j.gfj.2017.03.001

Garcia, A. S., Mendes-Da-Silva, W., \& Orsato, R. J. (2017). Sensitive industries produce better ESG performance: Evidence from emerging markets. Journal of cleaner production, 150, 135-147.

Halbritter, G., \& Dorfleitner, G. (2015). The wages of social responsibility — where are they? A critical review of ESG investing. Review of Financial Economics, 25-35.

Henke, H.-M. (2016). The effect of social screening on bond mutual fund performance. Journal of Banking \& Finance, 69-84.

Jain, A., Jain, P. K., \& Rezaee, Z. (2016). Value-Relevance of Corporate Social Responsibility: Evidence from Short Selling. Journal of Management and Accounting Research, 29-52.

KPMG. (2020). The KPMG Survey of Sustainability Reporting 2020. Retrieved from: https://home.kpmg/be/en/home/insights/2020/12/sus-the-kpmg-survey-of-sustainability-reporting2020.html

Limkriangkrai, M., Koh, S., \& Durand, R. B. (2017). Environmental, Social, and Governance (ESG) Profiles, Stock Returns, and Financial Policy: Australian Evidence. International Review of Finance, 17(3), 461-471. doi: 10.1111/irfi.12101

Ng, A. C., \& Rezaee, Z. (2015). Business sustainability performance and cost of equity capital. Journal of Corporate Finance, 34, 128-149. doi: https://doi.org/10.1016/j.jcorpfin.2015.08.003

Park, A., \& Ravenel, C. (2013). Integrating Sustainability Into Capital Markets: Bloomberg LP And ESG's Quantitative Legitimacy. Journal of Applied Corporate Finance, 25(3), 62-67. doi: 10.1111/jacf.12030

Porter, M., Serafaim, G., \& Kramer, M. (2019). Where ESG fail? Retrieved from: https://www.institutionalinvestor.com/article/b1hm5ghqtxj9s7/Where-ESG-Fails

RobecoSAM. (2019) SAM Corporate Sustainability Assessment 2019. Retrieved from: https://www.robecosam.com/csa/csa-resources/

Verheyden, T., Eccles, R. G., \& Feiner, A. (2016). ESG for All? The Impact of ESG Screening on Return, Risk, and Diversification. Journal of Applied Corporate Finance, 47-55. 